\title{
Immunohistochemistry and Biochemistry Features of Interstitial Mesenchymal Cells in Ischemic Cardiac Diseases
}

\author{
ZENAIDA CEAUSU ${ }^{1,2}$, BOGDAN SOCEA ${ }^{1,2^{*}}$, MIHAI DIMITRIU ${ }^{1,2}$, DIANA GHEORGHIU ${ }^{2}$, \\ IRINA PACU ${ }^{1,2}$, NICOLAE BACALBASA ${ }^{1,3}$, DRAGOS SERBAN ${ }^{1,4}$, \\ MARIANA COSTACHE ${ }^{1,4}$, MIHAI CEAUSU ${ }^{1,5}$ \\ ${ }^{1}$ Carol Davila University of Medicine and Pharmacy, 37 Dionisie Lupu Str., 020021, Bucharest, Romania \\ ${ }^{2}$ Sf. Pantelimon Emergency Clinical Hospital, 340-342 Soseaua Pantelimon, 021659, Bucharest, Romania \\ ${ }^{3}$ Dr. Ion Cantacuzino Clinical Hospital, 5-7 Ion Movila Str., 020475, Bucharest, Romania \\ ${ }^{4}$ Emergency Universitary Hospital, 169 Splaiul Independentei, 050098, Bucharest, Romania \\ ${ }^{5}$ Mina Minovici National Institute of Legal Medicine, 9 Soseaua Vitan-Barzesti, 042122, Bucharest, Romania
}

\begin{abstract}
In the cardiac remodelling game, the casting is represented by certain players in form of four mesenchymal cells: one main player, represented by the fibroblast /and three secondary players, represented by the endothelial cell, vascular smooth muscle cell and the cardiac stem cell. The fibroblast plays a role in recruiting inflammatory cells (PMN, macrophages) in the primary secretory phase and another role in extracellular matrix remodelling in the secondary proliferative phase. Myofibroblasts are mesenchymal cells that, due to their phenotype, are often described as a bridge between fibroblasts and smooth muscle. The endothelial cells and vascular smooth muscle cells are involved in vascular remodelling, while the cardiac stem cells are involved in cardiogenesis, but at a slow rate. Last, but not least, there are transient players, in the very first moments of the game, represented by the inflammatory cells (PMN, macrophages), which clean the injured (necrobiotic) area, paving the way for the myofibroblast to cardiac remodelling. Ischemic lesions, as well as cardiac tumours produce a large variety of symptoms and changes in extracellular matrix composition.
\end{abstract}

Keywords: extracellular matrix, mesenchymal cells, fibroblast, cardiac disease

\section{Introduction}

Cardiovascular diseases (CVD) represent the leading cause of mortality in the world. With major social health global impact, they exceed any other diagnostic group. Heart failure (HF) resumes the common final manifestation of most CVD. HF represents the hospitals' discharge leading diagnosis. Most patients associate other risk factor as well as dyslipidemia, diabetes and smoking, with hypertension and diabetes predominating in women and smoking more frequent in men [1].

Normal cardiac activity consists of a dynamic interaction between all cellular elements, both myocyte and non-myocyte cells [2,3]. Developing new treatments for CVD represents a novel challenge. It should start with a better understanding of the pathophysiology of hypoxic tissue damage, focusing on remodelling in organization and composition of the extracellular matrix (ECM), including fibroblasts, with conversion to myofibroblasts and cardiac stem cells. The aim of this review is an up to date characterisation of ECM composition and interactions between different cell types in cardiac ischemic lesions, which may provide new therapeutic targets for its treatment.

\section{Materials and methods}

We performed a narrative review by searching scientific databases (Pubmed, Scopus, Web of Science and EMBASE), between 1987 and 2020, regarding the composition of ECM and interactions between different cell types in cardiac ischemic lesions. Two author (ZC, BS) independently did the search job and data were analyzed by the other authors.

$\overline{\text { *email:bogdansocea@gmail.com; bogdan.socea@umfcd.ro }}$ 
The used key words were "extracellular matrix", "mesenchymal cells", "fibroblast", "cardiac disease", "stem cells" and combinations of them, like "cardiac stem cells".

\section{Results and discussions}

\section{The state of current knowledge}

\subsection{The fibroblast / myofibroblast}

Cardiac collagen network organization is established shortly after birth and this cardiac ECM is maintained in normal adult heart. The main cellular constituents of the cardiac tissue include $30 \%$ myocytes and $70 \%$ non-myocytes $[4,5]$. The space between cardiac myocytes, known as the cardiac ECM, is a dynamic microenvironment with multiple cell types, consisting of cardiac fibroblasts, myofibroblasts, endothelial cells, vascular smooth muscle cells, inflammatory cells and stem cells (Figure 1), that interact with each other in a very complex manner [6]. As for fibroblasts, they have long been recognized as important stromal cells, playing a key role in synthesizing extracellular matrix molecules and expression of fibrillar collagen. Fibroblasts' main roles are synthesis and posttranslational modification.

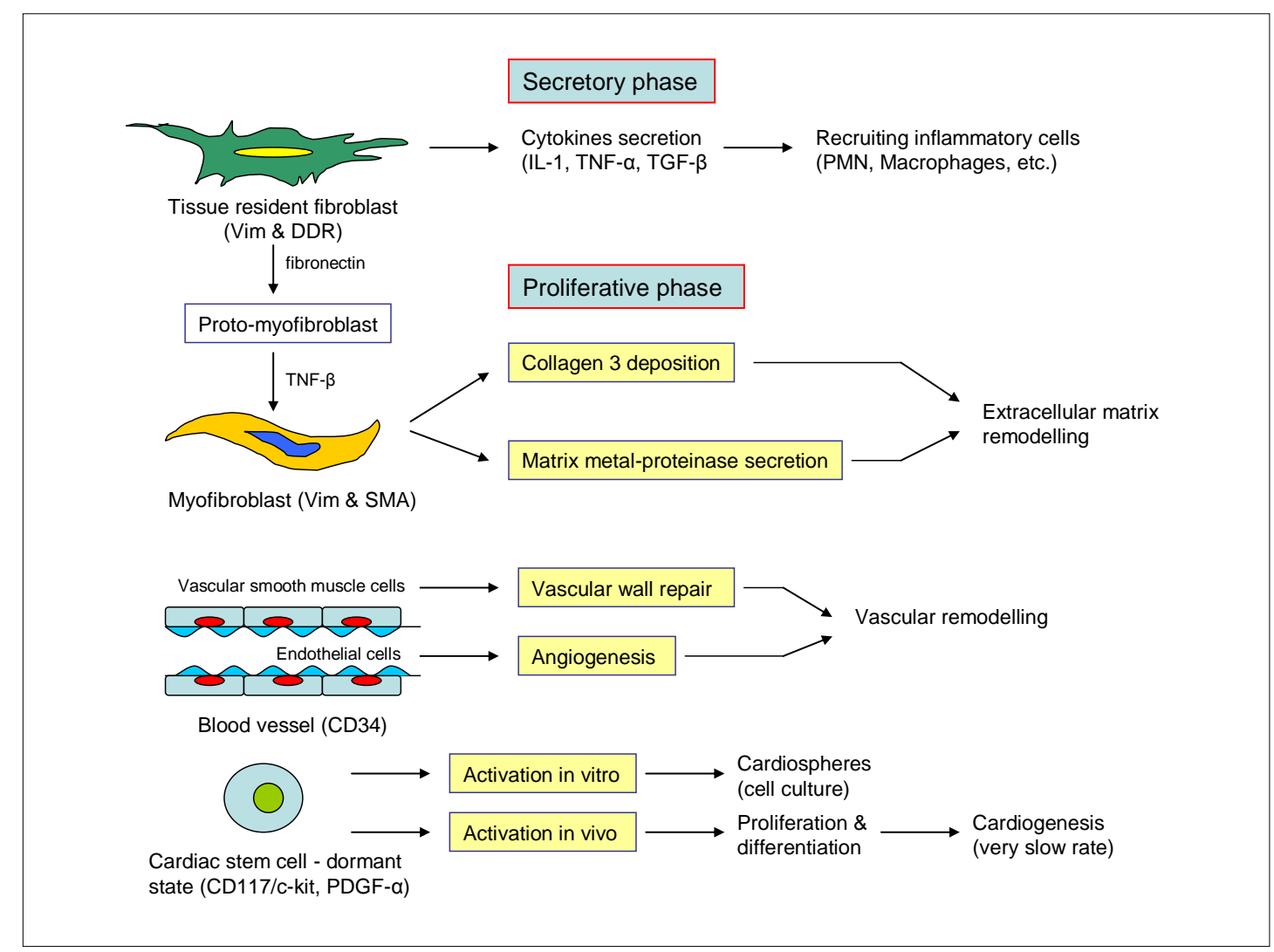

Figure 1. Different cell populations of the cardiac mesenchymal cro-environment and their functions

Cardiac fibroblasts (CF) proved to be derived from different cell populations, the epicardium is viewed as the main origin ( $80 \%$ ), followed by origin in endothelium/ endocardium, and neural crest [4]. In adult periods of ages, the proportion of fibroblasts are slightly higher [4]. Banerjee, studying the cell composition from different locations of the adult heart, observed that there was no significant difference $[4,5]$.

From the morphologically point of view, fibroblasts look flat, having a spindle shape, the main cell body emanating multiple extensions. Fibroblasts lack a basement membrane, this being a characteristic. Their Golgi apparatus is prominent, while rough endoplasmic reticulum is extensive [7]. They have an oval, speckled nucleus that typically has one or two nucleoli [7,8]. In culture in vitro, fibroblasts 
showed the ability to adhere to plastic cell culture plates. They can transmit electrical impulses between cardiomyocytes through intercellular gap junctions, leading to synchronized cardiomyocyte contractions [9]. The study of Masur SK, et al., 1996 [10] have demonstrated the phenotypic plasticity of fibroblasts cultured in vitro at low density. Cardiac regeneration, that is, restoration of the original structure and function in a damaged heart, differs from tissue repair, which involves collagen deposition and scar formation [11]. A number of factors, including known cytokine and growth factors, such as Tumor Necrosis Factor- $\alpha$ (TNF- $\alpha$ ), Interleukin (IL)-1, IL-10, chemokines, members of the Transforming Growth Factor- $\beta$ (TGF- $\beta$ ) family, IL-11, and Platelet-Derived Growth Factors (PDGF) are secreted in the cardiac interstitium, bind to cell surface receptors in fibroblasts, such as cytokine receptors, integrins, syndecans and CD44, and activate the fibrotic response. PDGRF $\alpha$ is strongly expressed by fibroblasts, whereas high PDGFR $\beta$ expression is associated with pericytes [12].

Myofibroblasts are mesenchymal cells that are often considered as a bridge between fibroblasts and smooth muscle, because of their phenotype. Physiologically, under normal conditions, fibroblasts ensure extracellular matrix homeostasis. Myofibroblasts could not be detectable in the heart at any significant level, with the exception of heart valve leaflets $[13,14]$. In response to various cardiac insults, such as myocardial infarction, pressure overload or ischemic injury, fibroblasts assume an activated phase. Myofibroblast phenotype express smooth muscle cell markers (smooth muscle actin) and contractile proteins and and will differentiate into myofibroblasts with an enhanced migratory and proliferative properties.

The transformation fibroblasts to myofibroblasts is modulated by TGF- $\beta 1$ [15]. Myofibroblasts are able to synthesize proteins of the extracellular matrix (fibroblasts have the same capacity, too). The isoform $\alpha$ of smooth muscle actin ( $\alpha$-SMA), which is myocyte-specific, becomes visible as stress fibres in cells. By these features, contractile force of the myofibroblasts is insured.

\subsection{Cardiac fibroblast / myofibroblast markers}

Several types of antibodies have been used to identify and characterize fibroblasts, but so far there is no specific marker for $\mathrm{CF}$, due to the marked phenotypic heterogeneity identified both within the localization in various tissues and at the level of the heart lesions under different physiological conditions. One of these is Vimentin, an intermediate filament protein composing the cell cytoskeleton. Vimentin can be found in a number of different cell types like endothelial cells, some immune system cells and fibroblasts, confirming their mesenchymal origin [16].

Another marker, member of the S100 intracellular calcium binding proteins, is represented by fibroblast specific protein (FSP1), also known as SA100A4. It was originally used for fibroblasts, but lacks specificity and is also expressed by hematopoietic and vascular cells [17, 18]. Adult embryonic fibroblasts, which come from numerous tissues, express FAP. This marker has been also detected on scar fibroblasts [19].

Another immunohystochemical marker for cardiac fibroblasts characterisation is Discoidin domain receptor 2 (DDR2) [20, 21]. DDR2 is a cell surface receptor that mediates many cellular functions, including growth, migration and differentiation. DDR2 was detected on only fibroblasts during heart development [22]. The epithelial and mesenchymal cells activated during epithelial-mesenchymal transformation as part of the development of atrioventricular valves also express DDR2 [23].

\subsection{Fibroblasts in ischemia}

Due to ischemic resistance, wide distribution in cardiac interstitial space, secretor and proinflammatory properties, fibroblasts are considered sentinel cells during ischemia, triggering an inflammatory reaction. The main mediators of the extracellular remodelling are matrix metalloproteinases (MMPs) [24]. Immediately after an ischemic episode CF in the infarcted heart, fibroblasts develop a pro-inflammatory phenotype secreting cytokines and chemokines as IL-1, TNF$\alpha$, TGF- $\beta$, oncostatin-M and they exhibit matrix-degrading properties enhancing MMP activity [24, 25, 26]. The next level in cardiac repair is suppression of inflammation and beginning of a proliferative 
phase. This is the time when fibroblasts become the main cell type in the infarcted myocardium and switch their secretory phenotype to a proliferative myofibroblast phenotype.

It is of interest to adopt new strategies for the specific influence of pathological cardiac fibrosis in the healing process, but without disturbing the adaptive healing response. For this purpose, the molecular mechanisms that control fibroblast plasticity and myofibroblast activation must be well understood. There are three main transcriptional regulatory axes which regulate fibroblast plasticity in differentiated heart tissue. The three axes are represented by: 1. TGF $\beta$ / Smad signaling; 2. Rho / myocardin-related transcription factor (MRTF) / serum response factor (SRF); 3. Calcineurin / transient receptor potential channel (TRP) / nuclear factor of activated T-Cell (NFAT) signaling [27] .

\subsection{The endothelial cells}

The endothelial cells line the inner wall of blood vessels and play an important role in the regulation of vascular tone, vascular permeability, and new vascular formation. They proliferate and play an important role in angiogenesis during ischemic heart disease, such as vascular thrombosis, infarction and fibrosis $[28,29]$. Their therapeutic potential due to mesenchymal properties could be speculated in the sense of regeneration and repair of the damaged myocardial tissue [30].

\subsection{Vascular smooth muscle cells}

Vascular smooth muscle cells (VSMCs) represents a small cell population of ECM, which has the property of expressing phenotypic and functional plasticity in response to vascular injuries. At the same time with vascular injury, VSMCs change from the 'contractile' phenotype to the 'proinflammatory' phenotype and production of pro-inflammatory mediators [31]. In recent years, many studies demonstrated that, during ischemic heart disease, VSMCs get activated for vascular wall repair, migrate and efficiently proliferate into the lesion. In the affected blood vessels and in pathological vascular remodelling, VSMCs become less differentiated at the pro-inflammatory signals.

\subsection{Inflammatory cells}

The fibroblasts play an important role in recruiting inflammatory cells (PMN, macrophages) in the primary secretory phase and another role in the cardiac ECM remodelling in the secondary proliferative phase. In ischemic cardiac disease, PMNs accumulate in the lesions within $24 \mathrm{~h}$. PMN accumulation has been demonstrated by marked PMNs [32]. PMNs participate in infection elimination and removal of dead tissue. Cardiac inflammatory macrophages gather in myocardial infarction tissue, being derived from circulating monocytes. Macrophages are also involved in ischemic tissue remodelling, resolution of inflammation, and cardiac remodelling. In all these processes, inflammatory cells interact with fibroblasts, monocytes and endothelial cells.

Monocyte chemoattractant protein-1 (MCP-1) is a pro-inflammatory chemokine up-regulated in failing myocardium, attracting circulating monocytes and macrophages into injured tissue [33, 34]. Myeloperoxidases derived from leucocytes is considered a cardiac ischemic biomarker [35]. MCP-1 mediates in the myocardium a controlled secretion of collagens and MMPs by CFs and determines their transformation into a myofibroblast phenotype [36, 37], as well as increased apoptotic activity [38]. MCP-1 induces up-regulation of pro-inflammatory cytokine production, MMP secretion, and adhesion molecule expression on monocytes [39, 40, 41], thus it is increased both their presence into ischemic heart tissue [42], and their proinflammatory characteristics. Moreover, MCP-1 determines the recruitment signal from bone marrow of CD34+/CD45+ fibroblast precursors into the cardiac tissue. They grow the endogenous CF population and determine an increased fibrotic behaviour [43, 44].

\subsection{The endogenous cardiac stem cells}

The new dynamic considerations show that both cell death and cell restoration in the ischemic lesions of the heart are a part of organ homeostasis, but the rate of myocyte renewal remains very low. During recent years, the interest of researchers has been directed towards the identification and 
characterization of many cardiac stem cells (CSCs) or resident cardiac progenitors, which are immature, but already committed cardiac cells. These cells can proliferate and mature into precursors expressing the stem cell surface marker c-kit in the adult heart [45].

Activated CSCs are pluripotent. They are involved in regeneration of the myocardium. In normal myocardium they are quiescent and adopt a dormant state (retaining the regenerative capacity), but they become activated in stress conditions, particularly in cardiac ischemia. Some studies [46, 47] showed that they are in close contact with telocytes, which may play a role in their activation.

CSCs concentrate in certain areas of cardiac tissue, such as the atrium or pericardium and form a heterogenic group of cells [48]. They express mesenchymal stem cell markers, like CD90 and CD105 and extra-cellular markers, like: Sox-2, Nanog, Rex1 [46, 47, 49]. ]. CSCs are part of the bigger family of adult stem and mesenchymal cells, also present in the gut and other adult tissues [50,51].

CSCs also express markers of early cardiac differentiation such as platelet derived growth factor receptor- $\alpha$ and fetal liver kinase-1, which allowed their identification [52]. CSCs include together progenitor cells, mesenchymal and stromal cells. Culture of biopsies obtained by endo-myocardial percutaneous punctures form spherical clusters of cells, 'cardiospheres'. These clusters could serve to harvest proliferative cells positive for progenitor cell-related antigens, or stromal and mesenchymal antigens, as well as other cellular populations with cardiac differentiation [53].

\section{Conclusions}

All myocardial cells are enmeshed within a dynamic network of ECM composed of many cell types, which not only serves a structural role and facilitates mechanical force transmission, but also interact dynamic to maintain the homeostasis and function of the heart, regulates cell phenotype and function.

A better understanding of the cellular composition of ECM will improve the cardiac therapies, focusing on genetics and proteomic profile. Fibroblasts and myofibroblasts represent the sun and the moon of myocardial remodelling. While the fibroblast is assumed to regulate homeostatic ECM remodelling, myofibroblasts act in adverse myocardial remodelling during cardiovascular disease.

It is not clear whether certain cellular precursors contribute only to fibroblast populations involved in specific pathologies (ischemic and reperfusion phenomena, infarction, cardiac overload), nor exactly what influences on fibroblastic remodelling have certain cells depending on their origin.

Expansion of our knowledge on the structure, proteomic profile, and functional properties of matrix constituents will help us to find new therapeutic opportunities in all cardiac injuries.

\section{References}

1. ANGHEL, L., PRISACARIU, C., GEORGESCU, C.A., Is There a Sex Difference of Cardiovascular Risk Factors in Patients with Acute Myocardial Infarction? Rev. Chim., 69(1), 2018, 255.

2. DIACONU, C.C., MANEA, M., MARCU, D.R., ET AL., The erectile dysfunction as a marker of cardiocascular disease: a review, Acta Cardiologica, 2019, doi: 10.1080/00015385.2019.1590498.

3. DIACONU, C., SALMEN, T., GAMAN, M.A., ET AL., SGLT2 inhibition in patients with type 2 diabetes and cardiovascular diseases: which are the benefits? Romanian Journal of Military Medicine, 122(1), 2019, 16.

4. DOPPLER, S.A., CARVALHO, C., LAHM H., ET AL., Cardiac fibroblasts: more than mechanical support, J. Thora. Dis, 9(Suppl 1), 2017, 36.

5. BANERJEE, I., FUSELER, J.W., PRICE, R.L., ET AL., Determination of cell types and numbers during cardiac development in the neonatal and adult rat and mouse, Am. J. Physiol. Heart Circ. Physiol., 293, 2007, 1883.

6. SEGERS, V.F., GEVAERT, A.B., BOEN, J.R., VAN CRAENENBROECK, E.M., DE KEULENAER, G.W., Epigenetic regulation of intercellular communication in the heart, Am. $J$. Physiol. Heart Circ. Physiol., 316, 2019, H1417. 
7. COLBY, A.S., STEPHANIE, L.K.B., TROY, A.B., Cardiac Fibroblast: The Renaissance, Cell. Circ. Res., 105(12), 2009, 1164.

8. CAMELLITI, P., BORG, T.K., KOHL, P., Structural and functional characterization of cardiac fibroblasts, Cardiovasc. Res., 65(1), 2005, 40.

9. MAEDEH, Z., ESRA, K., NGAN, F.H., Multicellular Interactions in 3D Engineered Myocardial Tissue, Front. Cardiovasc. Med., 5(147), 2018, 6.

10. MASUR, S.K., DEWAL, H.S., DINH, T.T., ET AL., Myofibroblasts differentiate from fibroblasts when plated at low density, Proc. Natl. Acad. Sci. USA, 93(9), 1996, 4219.

11. KRENNING, G., ZEISBERG, E.M., KALLURI, R., Myofibroblasts differentiate from fibroblasts when plated at low density, J. Cell. Physiol., 225(3), 2010, 631.

12. FRANGOGIANNIS, N.G., Cardiac fibrosis: Cell biological mechanisms, molecular pathways and therapeutic opportunities, Mol. Aspects Med., 65, 2019, 70.

13. BAUM, J., DUFFY, H.S., Fibroblasts and myofibroblasts: What are we talking about? J. Cardiovasc. Pharmacol., 57(4), 2011, 376.

14. PORTER, K.E., TURNER, N.A., Cardiac fibroblasts: at the heart of myocardial remodelling, Pharmacol. Ther., 123, 2009, 255.

15. TARBIT, E., SINGH, I., PEART, J.N., ROSE'MEYER, R.B., Biomarkers for the identification of cardiac fibroblast and myofibroblast cells, Heart Fail Rev., 24(1), 2019, 1.

16. BELTRAMI, A.P., BARLUCCHI, L., TORELLA, D., ET AL., Adult cardiac stem cells are multipotent and support myocardial regeneration, Cell, 114, 2003, 763.

17. SHINDE, A.V., FRANGOGIANNIS, N.G., Fibroblasts in myocardial infarction: a role in inflammation and repair, J. Mol. Cell Cardiol., 70, 2014, 74.

18. KONG, P., CHRISTIA, P., SAXENA, A., ET AL., Lack of specificity of fibroblast-specific protein 1 in cardiac remodeling and fibrosis, Am. J. Physiol. Heart Circ. Physiol., 305(1), 2013, 363.

19. RETTIG, W.J., GARIN-CHESA, P., BERESFORD, H.R., ET AL., Cell-surface glycoproteins of human sarcomas: differential expression in normal and malignant tissues and cultured cells, Proc. Natl. Acad. Sci., 85, 1988, 3110.

20. SHRIVASTAVA, A., RADZIEJEWSKI, C., CAMPBELL, E., ET AL., An orphan receptor tyrosine kinase family whose members serve as nonintegrin collagen receptors, Mol. Cell., 1, 1997, 25. 21. VOGEL, W., GISH, G.D., ALVES, F., PAWSON, T., The Discoidin domain receptor tyrosine kinases are activated by collagen, Mol. Cell., 1, 1997, 13.

22. GOLDSMITH, E.C., HOFFMAN, A., MORALES, M.O., ET AL., Organization of Fibroblasts in the Heart. Devel. Dyn., 230, 2004, 787.

23. GOLDSMITH, E.C., ZHANG, X., WATSON, J., ET AL., The collagen receptor DDR2 is expressed during early cardiac development, Anat. Rec., 293, 2010, 762.

24. DIMA-COZMA, L.C., COZMA, S., HINGANU, D., GHICIUC, C.M., MITU, F., Targeting matrix metalloproteinases in atherosclerosis and cardiovascular dysfunction, Rev. Chim., 70(2), 2019, 718.

25. SANDANGER, O., RANHEIM, T., VINGE, L.E., ET AL., The NLRP3 inflammasome is upregulated in cardiac fibroblasts and mediates myocardial ischemia-reperfusion injury, Cardiovasc. Res., 99, 2013, 164.

26. SIWIK, D.A., PAGANO, P.J., COLUCCI, W.S., Oxidative stress regulates collagen synthesis and matrix metalloproteinase activity in cardiac fibrosis, Am. J. Physiol. Cell. Physiol., 280, 2001, 53.

27. LIGHTHOUSE, J.K., SMALL, E.M., Transcriptional control of cardiac fibroblast plasticity, $J$. Mol. Cell. Cardiol., 91, 2016, 52.

28. ROSS, R.S., BORG, T.K., Integrins and the myocardium, Circ. Res., 88, 2001, 1112.

29. HUDON-DAVID, F., BOUZEGHRANE, F., COUTURE, P., THIBAULT, G., THY-1 expression by cardiac fibroblasts: lack of associate with myofibroblast contractile markers, J. Mol. Cell. Cardiol., 42(5), 2007, 991.

30. TALIOR-VOLODARSKY, I., CONNELLY, K.A., ARORA, P.D., ET AL., $\alpha 11$ integrin stimulates myofibroblast differentiation in diabetic cardiomyopathy, Cardiovasc. Res., 96, 2012, 265. 
31. NAGALINGAM, R.S., SAFI, H.A., CZUBRYT, M.P., Gaining myocytes or losing fibroblasts: Challenges in cardiac fibroblast reprogramming for infarct repair, J. Mol. Cell. Cardiol., 2015, JMCC9596.

32. BELL, D., JACKSON, M., Millar, A.M., Nicoll, J.J., Connell, M., MUIR, A.L. The acute inflammatory response to myocardial infarction: imaging with indium-111 labelled autologous neutrophils, Br. Heart J., 57, 1987, 23-27.

33. MARTIN, M.L., BLAXALL, B.C., Cardiac intercellular communication: are myocytes and fibroblasts fair-weather friends? J. Cardiovasc. Transl. Res., 5(6), 2012, 768.

34.FRANGOGIANNIS, N.G., Chemokines in the ischemic myocardium: From inflammation to fibrosis, Inflamm. Res., 53, 2004, 585.

35.COCULESCU, B.I., MANOLE, G., DINCA, A., HARSOVESCU, T., TUDORACHE, I.S., The possible serum complex-biomarkers for the early diagnosis of diastolic dysfunction with preserved systolic function, Rev. Chim., 70(6), 2019, 2229.

36.GHARAEE-KERMANI, M., DENHOLM, E.M., PHAN, S.H., Costimulation of fibroblast collagen and transforming growth factor beta1 gene expression by monocyte chemoattractant protein-1 via specific receptors, J. Biol. Chem., 271, 1996, 17779.

37.YAMAMOTO, T., ECKES, B., MAUCH, C., HARTMANN, K., KRIEG, T., Monocyte chemoattractant protein-1 enhances gene expression and synthesis of matrix metalloproteinase-1 in human fibroblasts by an autocrine IL-1 alpha loop, J. Immunol., 164, 2000, 6174.

38. BIDZHEKOV, K., ZERNECKE, A., WEBER, C., MCP-1 induces a novel transcription factor with proapoptotic activity, Circ. Res., 98, 2006, 1107.

39. JIANG, Y., BELLER, D.I., FRENDL, G., GRAVES, D.T., Monocyte chemoattractant protein-1 regulates adhesion molecule expression and cytokine production in human monocytes, J. Immunol., 148, 1992, 2423.

40.SPINALE, F.G., Myocardial matrix remodeling and the matrix metalloproteinases: Influence on cardiac form and function, Physiological reviews, 87, 2007, 1285.

41.BAN, K., IKEDA, U., TAKAHASHI, M., ET AL., Expression of intercellular adhesion molecule-1 on rat cardiac myocytes by monocyte chemoattractant protein-1, Cardiovasc. Res., 28, 1994, 1258.

42.BIRDSALL, H.H., GREEN, D.M., TRIAL, J., ET AL., Complement C5a, TGF-beta 1, and MCP-1, in sequence, induce migration of monocytes into ischemic canine myocardium within the first one to five hours after reperfusion, Circulation, 95, 1997, 684.

43.HAUDEK, S.B., CHENG, J., DU, J., ET AL., Monocytic fibroblast precursors mediate fibrosis in angiotensin-II-induced cardiac hypertrophy, J. Mol. Cell. Cardiol., 49, 2010, 499.

44.XU, J., LIN, S.C., CHEN, J., ET AL., CCR2 mediates the uptake of bone marrow-derived fibroblast precursors in angiotensin induced cardiac fibrosis, Am. J. Physiol. Heart Circ. Physiol., 301, 2011, 538.

45.DIXIT, P., KATARE, R., Challenges in identifying the best source of stem cells for cardiac regeneration therapy, Stem Cell. Res. Ther., 6(1), 2015, 26.

46.POPESCU, L.M., MANOLE, E., SERBOIU, C.S., MANOLE, C.G., SUCIU, L.C., GHERGHICEANU, M., POPESCU, B.O., Identification of telocytes in skeletal muscle interstitium: implication for muscle regeneration, J. Cell. Mol. Med., 15(6), 2011, 1379.

47.AlBUlESCU, R., TANASE, C., CODRICI, E., POPESCU, D.I., CRETOIU, S.M., POPESCU, L.M., The secretome of myocardial telocytes modulates the activity of cardiac stem cells, J. Cell. Mol. Med., 19(8), 2015, 1783.

48.NADAL-GINARD, B., KAJSTURA, J., LERI, A., ANVERSA, P., Myocyte death, growth, and regeneration in cardiac hypertrophy and failure, Circ. Res., 92, 2003, 139.

49. TATEISHI, K., ASHIHARA, E., HONSHO, S., ET AL., Human cardiac stem cells exhibit mesenchymal features and are maintained through AKT/GSK-3beta signaling, Biochem. Biophys. Res. Commun., 352, 2007, 635. 
50. MEHEDINTU, C., BRINDUSE, L.A., BRATILA, E., ET AL., Does computed tomography-based virtual colonoscopy improve the accuracy of preoperative assessment based on magnetic resonance imaging in women managed for colorectal endometriosis?, J Minim Invasive Gynecol., 25(6), 2018, 1009.

51. BRATILA, E., COMANDASU, D., COROLEUCA, CA, ET AL., Gastrointestinal symptoms in endometriosis correlated with the disease stage, ISI Proceedings, XXXVIth National Congress of Gastroenterology, Hepatology and Digestive Endoscopy, Filodiritto Editore, 2016, 67.

52. CHONG, J.J., REINECKE, H., IWATA, M., ET AL., Progenitor cells identified by PDGFR-alpha expression in the developing and diseased human heart, Stem Cells Dev., 22, 2013, 1932.

53._SMITH, R.R., BARILE, L., CHO, H.C., ET AL., Regenerative potential of cardiosphere-derived cells expanded from percutaneous endomyocardial biopsy specimens, Circulation, 115, 2007, 896.

$\overline{\text { Manuscript received: } 17.03 .2020}$ 